\title{
Relações interfirmas e emprego na rede de empresas: a experiência de externalização de uma empresa no setor de telecomunicações ${ }^{1}$
}

SANDRO RUDUIT*

Introdução

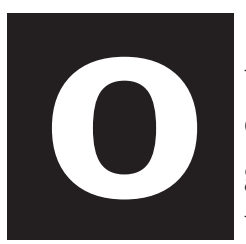

processo de reestruturação produtiva e econômica conforma sistemas de produção que se caracterizam, entre outros aspectos, pela externalização de tarefas, desde vigilância até sofisticados projetos de engenharia, visando à flexibilização, com baixos custos, do trabalho e da produção. A rede de empresas é a unidade de produção formada a partir da constelação de relações de complementaridade e de poder interfirmas, em face da transferência de segmentos do processo produtivo de uma empresa a fornecedores (grandes, médios e pequenos) de produtos, serviços ou mão-de-obra. Ela conjuga variavelmente diversos padrões de relacionamento interempresas (subordinação, cooperação) e práticas de emprego (virtuosas/ não-precárias, restritivas/ precárias), sobre os quais incidem circunstâncias tanto de ordem técnico-econômica como societal e institucional.

\footnotetext{
*Doutorando no Programa de Pós-Graduação em Sociologia da Universidade Federal do Rio Grande do Sul. E-Mail: ruduit@vortex.ufrgs.br

1 O presente texto apresenta aspectos de minha dissertação de mestrado Relações interfirmas e emprego: estudo de uma rede de empresas em telecomunicações. Sou grato à Profa. Dra. Cinara Rosenfield pelos comentários à versão preliminar deste artigo e à CAPES pela concessão da bolsa durante o programa de mestrado.
} 
A principal empresa do setor de telecomunicações, no Estado do Rio Grande do Sul, a Companhia Riograndense de Telecomunicações (CRT), experimentou, na década passada, a alteração das suas formas de trabaIho, de produção e de atuação no mercado, através (1) da intensa atualização tecnológica e ampliação da planta telefônica, (2) da sua flexibilização organizacional e enxugamento do quadro de funcionários, intensificando a externalização de tarefas, e (3) da sua privatização, em 1998, e liberalização do mercado de telefonia fixa, no ano de 2000. A CRT passou a liderar uma rede de empresas, aplicadas na ampliação e na atualização tecnológica da sua malha telefônica, cujo sistema de relações interempresas e cujas práticas de emprego são notoriamente diversificados. As empresas estruturam-se em distintos segmentos de serviços (instalação de terminais telefônicos, cabeamento metálico, redes ópticas, digitalização de centrais de comutação), com variável complexidade técnica e em diferentes camadas/ níveis de fornecedores (terceirização, "quarterização", "quinterização" e "sexterização").

O objetivo deste artigo consiste na discussão dos fatores que promovem a diferenciação das relações interfirmas e do emprego, no âmbito da rede de empresas, a partir do exame da trama produtiva liderada pela CRT após o processo de reestruturação/ privatização da empresa, nos anos 90.

A pesquisa empírica consistiu na investigação (1) da empresa central - CRT; (2) de três empresas contratadas diretamente pela CRT (terceiras), abarcando três segmentos de fornecedores (com distintos níveis de complexidade técnica: instalação de terminais telefônicos, cabeamento metálico e óptico, digitalização de centrais de comutação); (3) de quatro empresas contratadas pelas empresas terceiras, isto é, num segundo nível de prestação de serviços; (4) de duas empresas localizadas no terceiro nível de prestação de serviços; e (5) de uma empresa situada no quarto nível de prestação de serviços. Houve, portanto, dois critérios para a seleção das onze empresas pesquisadas: primeiro, abarcar diferentes segmentos (com 
distintos níveis de complexidade técnica) de prestação de serviços, na medida em que se supunha que, além da estratégia competitiva da empresa contratante, o tipo de serviço prestado pela empresa contratada influiria na natureza das relações interempresas; segundo, abranger diferentes camadas de prestação de serviços, em face da suposição de que a posição da empresa nos níveis da rede, bem como as relações interfirmas, interfeririam nas práticas de emprego. Todas as empresas têm sede na Região Metropolitana de Porto Alegre, embora realizem serviços no interior do Estado e algumas, fora dele.

O presente texto está divido em quatro seções, além desta introdução: na primeira, apresentam-se aspectos da dinâmica de reestruturação da empresa central e da conformação de sua estratégia competitiva; na segunda, examinam-se os padrões de relacionamento interfirmas; na terceira, discutem-se as práticas de emprego no âmbito da rede de empresas; finalmente, destacam-se as principais conclusões e contribuições da análise.

\section{Reestruturação e estratégia competitiva da empresa central}

As análises dos processos recentes de transformação no universo do trabalho apresentam argumentações divergentes, porquanto se realizam através da observação de variados objetos de investigação e da construção de diferentes perspectivas teóricas. Há análises otimistas que advogam em favor da natureza virtuosa dos atuais processos de transformação, centrando a argumentação em aspectos relativos à produção, à produtividade e à competitividade; pessimistas que os interpretam como portadores de implicações sociais deletérias, associadas à dinâmica do capitalismo; e não-dualistas que os compreendem como fenômenos multidimensionais, rejeitando modelos pré-constituídos de análise e interessando-se pelos processos geradores de diferentes trajetórias das sociedades, regiões, setores e mesmo empresas².

2 Para uma análise detalhada dessas perspectivas teóricas, ver Ruduit (2001), mormente o Capítulo 1 - A transfiguração das formas de trabalho e a rede de empresas. 
Desde uma perspectiva não-dualista, compreende-se que, por mais que obedeçam às regras de mercado e à lógica produtiva globais, as redes de empresas são significativamente afetadas pelas características institucionais e societais locais (Castells, 1999). As variadas dimensões do ambiente social afetam a dinâmica da rede através do condicionamento que exercem sobre a estratégia competitiva da empresa central. A estratégia competitiva adotada pela empresa é o elemento que orienta a dinâmica de reestruturação e, por extensão, de configuração da rede de empresas. A definição da estratégia competitiva resulta, por sua vez, da conjugação de fatores relativos a diferentes dimensões do ambiente social, quais sejam o tipo de serviço final da rede (dimensão técnica), as condições de mercado da empresa central (dimensão econômica), o padrão de uso da força de trabalho (dimensão societal) e os vínculos sociais dos atores (dimensão institucional).

Estudos recentes sobre o setor de telecomunicações estão, de certo modo, a ratificar uma perspectiva de análise não-dualista. A expansão e a reestruturação do setor, nas décadas de 80 e de 90, são uma imposição em diferentes países da Europa, da Ásia e das Américas, em razão de que ele constitui a base material sobre a qual se apóia a economia globalizada (Castells, 1999; Larangeira, 1998), atraindo intenso interesse comercial (Coutinho, 1995). De fato, no ano de 1995, enquanto o PIB mundial teve um incremento de apenas 3,5\%, a taxa de crescimento do setor de telecomunicações foi precisamente o dobro: 7\% (PASTE, 1997). No Brasil, em 1999, enquanto o PIB brasileiro cresceu apenas 0,8\%, a telefonia fixa apresenta expansão de 25,5\% (PASTE, 2000). No entanto é notável que a forma como a reestruturação do setor de telecomunicações se realiza, bem como os arranjos que produz, são heterogêneos, variando de acordo com as características de cada sociedade - conflitualidade entre os atores sociais, trajetória do setor, conjuntura política e econômica nacional (Larangeira, 1998; Pessini e Maciel, 1995; Walter, 1998). 
A CRT apresenta certas peculiaridades na sua trajetória de reestruturação. Ela foi a primeira empresa do sistema brasileiro de telecomunicações a ser privatizada. As empresas de telecomunicações, no Brasil, atuavam como monopólios estatais, até o início da década de 90. A insuficiência dos investimentos do Estado, a influência de agências internacionais de financiamento, mormente o Fundo Monetário Internacional (FMI) e o Banco Mundial (BM), sobre o Governo, bem como o interesse de investidores privados estrangeiros (entre eles, a Telefónica de España) induziram a reestruturação do setor no País, expressa na atualização tecnológica e na expansão da rede, combinadas com privatização de empresas e com liberalização do mercado (Coutinho, 1995; Larangeira, 1998). Assim, em dezembro de 1996, o Governo do Estado opta pela venda de 35\% das ações da empresa para o consórcio liderado pela Telefónica Internacional de España S/A, associada ao Banco Bilboa Viscaya, à Portugal Telecom, à Telefónica de Argentina S/A e à Companhia Telecomunicaciones de Chile S/ $A$. Foi então que a empresa iniciou um radical processo de reestruturação técnica e organizacional. Em junho de 1998, o Governo do Estado vendeu a maioria de suas ações para o consórcio liderado pela Telefónica de España, que passou a deter 85,12\% das ações com direito a voto (Gazeta Mercantil, 29/30/31.10.99, p.A10). Em julho de 2000, o consórcio liderado pela Telefónica desvinculou-se do controle da empresa, repassando-o ao consórcio liderado pela Brasil Telecom S/A. A liberalização do mercado nos serviços de longa distância nacional iniciou em julho de 1999, com a implantação do Código de Seleção de Prestadora (CSP). Em novembro do ano 2000, entrou em operação a chamada "empresa-espelho", a Global Village Telecom (GVT), liberalizando o mercado de telefonia fixa local.

O tipo de serviço da empresa central e, por extensão, da rede, condiciona a estratégia competitiva, no seguinte sentido: produtos/ serviços de alta tecnologia tenderiam a associar-se a estratégias competitivas apoiadas na qualidade do produto, geralmente voltadas para mercados segmentados, embora não anule a necessidade de redução de custos; em contrapartida, produtos/ serviços de baixa tecnologia tendem a associar-se a estratégias competitivas apoiadas no preço do produto, através da redução 
de custos, geralmente voltadas para mercados massificados (Gitahy et al., 1997; Gitahy e Cunha, 1999). A situação da CRT é ambígua neste aspecto. Por um lado, ela vem adotando uma série de medidas para a atualização tecnológica e para a diversificação dos seus serviços, das quais se destacam a crescente digitalização das centrais de comutação ${ }^{3}$ (conforme se observa na Tabela 1). A expansão da digitalização permitiu a criação, pela empresa, de dez novos serviços, disponibilizados para atender às propriedades específicas de clientes grandes, pequenos, residenciais e comerciais. Por outro lado, ela é obrigada por exigências contratuais (que serão a seguir analisadas) a atender a um mercado de massa cujo fator fundamental de concorrência é o preço dos serviços.

Tabela 1. Indicadores de reestruturação da Companhia Riograndense de Telecomunicações - 1995 a 1999

\begin{tabular}{|c|c|c|c|c|c|}
\hline Indicadores & 1995 & 1996 & 1997 & 1998 & 1999 \\
\hline Digitalização da planta (em \%) & 37,4 & 51,2 & 59,9 & 71,2 & 995,4 \\
\hline Linhas fixas em serviço (em milhares) & 682 & 783 & 1040 & 1448 & 1630 \\
\hline $\begin{array}{l}\text { Densidade telefônica no Estado } \\
\text { (linhas fixas em serviço/100 hab.) }\end{array}$ & 7,2 & 8,2 & 10,7 & 14,9 & 16,6 \\
\hline $\begin{array}{l}\text { Investimento em obras de rede } \\
\text { (em milhões de reais) }\end{array}$ & 226 & 405 & 809 & 700 & 269 \\
\hline $\begin{array}{l}\text { Receita líquida dos serviços } \\
\text { (em milhões de reais) }\end{array}$ & 461 & 728 & 938 & 1039 & 1140 \\
\hline Empregados & 5846 & 4451 & 4640 & 3919 & 3724 \\
\hline $\begin{array}{c}\text { Produtividade } \\
\text { (linhas fixas em serviço/empregado) }\end{array}$ & 130 & 213 & 299 & 367 & 418 \\
\hline $\begin{array}{c}\text { Custo do pessoal total em relação à receita } \\
\text { líquida (em \%) }\end{array}$ & 52 & 34 & 26 & 21 & - \\
\hline
\end{tabular}

Fonte: Composição a partir dos Relatórios Anuais da CRT, 1995 a 1999.

3 As centrais digitais são mais compactas, admitem número superior de assinantes, apresentam menos falhas de transmissão e consomem menos energia, do que as suas antecessoras, as eletromecânicas (Gazeta Mercantil, 1997). 
As condições de mercado da empresa centra/ referem-se aos limites e às possibilidades de produção e de comercialização de seus serviços, definidos pelas características e tendências do setor e da região nos quais opera. Tanto contextos de crise e de instabilidade na economia regional e setorial como produtos destinados a consumidores de baixa renda estimulam as empresas a competirem no mercado por meio exclusivo de preços baixos, desenvolvendo estratégias competitivas de redução de custos. Contextos econômicos de crescimento e de estabilidade e produtos destinados a consumidores de alta renda favoreceriam estratégias de competição no mercado, voltadas para a qualidade dos serviços (Gereffi, 1997; Gitahy e Cunha, 1999).

Após a privatização parcial, em 1996, a CRT incrementou significativamente o investimento em obras de rede telefônica (vide Tabela 1), permitindo expandir o número de linhas fixas em serviço (conforme se observa na Tabela 1) e atender às pressões institucionais materializadas nas metas e nas obrigações estabelecidas no Contrato de Concessão de Serviços (celebrado entre CRT, Agência Nacional de Telecomunicações - Anatel ${ }^{4}$ - e Governo do Estado) e no Contrato de Gestão (firmado entre consórcio comprador, CRT e Governo do Estado), que previa a instalação de quarenta mil linhas telefônicas ao mês, durante o ano de 1998. Dessa forma, a densidade telefônica no Estado do Rio Grande do Sul, expressa na razão do número de linhas em serviço por habitante, vem elevando-se (vide Tabela 1).

Paralelamente, a CRT reestruturou as suas tarifas, elevando-as sobretudo para os clientes residenciais. No período de 1994 a 2000, enquanto o INPC (Índice Nacional de Preços ao Consumidor) variou 86, 9\%, a tarifa de assinatura residencial mensal aumentou $3241 \%$ e a não-residencial $522,6 \%$ (Sinttel/RS, O Parceiro, setembro de 2000, Encarte Especial). Por conseqüente, o crescimento do número de linhas em serviço, apoiado no 
incremento do investimento de capital em obras de rede, associado à reestruturação tarifária repercutiram na ampliação da receita líquida dos serviços prestados pela CRT (vide Tabela 1).

O padrão de uso da força de trabalho expressa os desdobramentos relativos à forma como o fator trabalho é usado em uma empresa ou região, ao longo de certo período, resultando das características da força de trabalho (instrução, treinamento) e da dinâmica de conflitualidade entre os atores sociais. Consoante ao que argumentam Leda Gitahy et al. (1997), padrões de uso da força de trabalho nos quais a mão-de-obra tem baixo custo, existe exército industrial de reserva e há frágeis instituições de regulação das relações de trabalho, o que estimularia as empresas a adotarem estratégias competitivas de redução de custos, uma vez que haveria reduzida limitação ao capital relativamente à exploração do trabalho.

A Tabela 1 evidencia que, enquanto o número de empregados vem declinando, a produtividade vem aumentando, em razão de que, simultaneamente, a CRT reduziu drasticamente o emprego e ampliou expressivamente o número de linhas fixas em serviço. Os que permaneceram empregados enfrentam a intensificação do ritmo de trabalho e a alteração dos benefícios sociais: foram extintos ou reduzidos, sobretudo, os referentes aos ganhos monetários e à proteção ao emprego, e foram auferidas vantagens, como a ampliação dos planos de assistência médica e a compensação de horas de trabalho por horas-aula.

A ampliação da planta da CRT implicou a exigência de maior capacidade de trabalho, a qual, face à redução do quadro de funcionários, no mesmo período, foi suprida através do incremento da produtividade (pelo uso de novas tecnologias e da intensificação do ritmo de trabalho) e da expansão da externalização de trabalho. Tarefas anteriormente realizadas na empresa foram terceirizadas, tais como telemarketing teleatendimento, e foi ampliada a terceirização nas áreas de instalação e de manutenção de rede. $\mathrm{O}$ volume de gastos com serviços de terceiros variou positivamente 
de 119 milhões de reais, em 1998, para 220 milhões de reais, em 1999 (DIEESE, 2000, p. 3). Segundo estimativa de um informante, o número de trabalhadores vinculados às empresas terceiras nos segmentos de cabeamento e de instalação de terminais evoluiu de cerca de 800 trabaIhadores, em 1996, para cerca de 4100, em 2000 (Entrevista com Diretor do Sinttel/RS, Porto Alegre, 05/08/00).

As mudanças no uso da força de trabalho (redução do emprego, elevação da produtividade, terceirização) permitiram à Companhia reduzir drasticamente a participação dos gastos com pessoal na receita líquida da empresa (vide Tabela 1).

Os vínculos sociais dos atores seriam, na acepção atribuída por Scott Martin (1997), as redes de relações, internas e externas ao universo do trabalho, estabelecidas pelos atores sociais. Vínculos sociais mais sólidos estimulariam uma institucionalidade favorável à negociação dos processos de reestruturação e de transformação dos padrões de uso da força de trabalho. Inversamente, vínculos frágeis estimulariam uma institucionalidade voltada para a imposição dos processos de transição (Martin, 1997).

No caso da CRT, por um lado, os vínculos sociais dos trabalhadores eram relativamente frágeis no momento em que se iniciou o processo de reestruturação/ privatização, em razão da drástica redução de pessoal, que acuou a categoria e que reduziu a base de filiados, da fragmentação do coletivo de trabalhadores, em face do incremento da terceirização e do fato de o Sinttel/RS (Sindicado dos Telefônicos e dos Operadores de Mesas Telefônicas do Rio Grande do Sul) não aceitar a filiação dos trabalhadores das empresas terceiras, e da ausência de vínculos dos trabalhadores e do Sinttel/RS com atores externos, tais como partidos, centrais sindicais e outros sindicatos 5 . Por outro lado, o consórcio comprador, liderado pela Telefónica, detinha extensa experiência em processos de transformação do

5 A Telefónica de Españaé a nona empresa no ranking mundial de telecomunicações, com uma receita de operação anual de mais de 15 bilhões de dólares / ano e com mais de 92 mil empregados, atuando em cerca de 30 empresas de diversos países: Espanha, Chile, Argentina, México, Costa Rica, Brasil e outros (Fonte: www.fittel.org.br). 
uso de mão-de-obra e de conflitualidade com trabalhadores e sindicatos. Nessas circunstâncias, fragilizou-se a oposição do Sinttel/RS à reestruturação/ privatização da CRT. A ação da nova direção foi marcada pela imposição das mudanças. A ação sindical caracterizou-se pelo caráter defensivo, de negação das inovações. Contudo, o Sinttel/RS vem realizando campanhas de sindicalização entre trabalhadores das empresas subcontratadas pela CRT e de trabalhadores das demais empresas de telecomunicações no Estado (Telet, Telefonica Celular, GVT), a fim de ampliar sua base de filiados, resultando na celebração de Acordos Coletivos de Trabalho com três empresas em 2000: a Visabrás, a Pampa e a AS Júnior.

A estratégia competitiva indicaria as formas de atuação no mercado adotadas por uma empresa, implicando a orientação dos processos de reestruturação e dos objetivos a serem alcançados com a externalização de trabalho. Por isso, ela interfere nas relações estabelecidas entre empresa contratante e empresas contratadas. Ela pode variar entre formas voltadas predominantemente para a redução de custos, a fim de competir no mercado através de preços baixos, e formas de competição apoiadas na qualidade dos serviços/ produtos (Gitahy, 1994; Gitahy et al., 1997).

Segundo dados do DIEESE (2000), dos 37 indicadores definidos pela Anatel, a CRT não atingiu as metas estabelecidas para 9 deles, considerando-se o seu desempenho médio nos nove primeiros meses do ano de 2000 (dados disponíveis até o encerramento da coleta de dados). O desempenho insatisfatório concentra-se nos indicadores de qualidade dos serviços (8 entre os 9 não contemplados), particularmente nos de qualidade da rede (7 entre os 9), área expressivamente terceirizada pela empresa.

A forma e os critérios de contratação de empresas terceiras vêm modificando-se. Logo após a privatização, atendidas as exigências legais ${ }^{6}$, a Companhia contratava empresas com o critério de menor preço, gerando três tipos de problemas: 1) a contratação de inúmeras empresas dificultava 
o controle e a fiscalização dos serviços prestados; 2) o controle dos serviços pela Anatel impôs à CRT a necessidade de melhorar os serviços de rede; e 3) o repasse de obras de pequeno e de médio portes não só dificultava a redução de custos dos serviços com ganhos de escala, mas também exigia que a CRT tivesse que repassar os valores contratados durante a obra, pois pequenas e médias empresas não dispõem de capital social suficiente para custear despesas a longo prazo. Então, a partir de 1999, as formas de contratação adotadas pela Companhia são a concorrência por menor preço e o convite, realizado em casos nos quais a empresa apresenta baixo desempenho nos indicadores da Anatel, os prazos para o cumprimento da meta está esgotando-se (não havendo tempo hábil para realizar concorrência) e os processos técnicos são de domínio exclusivo de uma, ou de poucas empresas. Os critérios são certo volume de capital social, atendimento das normas legais e menor valor cobrado pelos serviços. Em razão da mudança nos critérios, a CRT passou a contratar poucas grandes empresas para realizar "pacotes de obras". As micro, pequenas e médias empresas foram eliminadas dos processos de seleção de prestadoras de serviços, passando a fornecer serviços às empresas terceiras.

A redução do quadro de pessoal da CRT implicou menor número de fiscais dos serviços terceirizados. A fiscalização do trabalho passou a concentrar-se mais na documentação das empresas (agora em menor número) do que na observação in loco dos serviços (equipamentos, materiais, procedimentos, normas técnicas).

Portanto, a estratégia competitiva da CRT apóia-se na redução de custos (desempenho insatisfatório nos indicadores da Anatel; contratação de empresas através do menor valor, sem exigência de certificados de qualidade e de capacitação da mão-de-obra; frágil fiscalização), em razão da conjugação de variados fatores relativos ao ambiente social: 1) o emprego de alta tecnologia possibilita a diversificação e a adequação dos serviços a diversos segmentos de mercado; 2) a empresa atua, regulada por instituições sociais - 
Anatel e contratos de concessão e de gestão, em um mercado de massa em plena expansão - incremento nas linhas em serviço, no investimento e na receita; 3) a privatização e a reestruturação da empresa pressionam para a modificação do padrão de uso da mão-de-obra, no sentido da redução de custos com trabalho, com papel importante desempenhado pela terceirização, pela redução do emprego e dos benefícios e pelo aumento da produtividade; e 4) os trabalhadores apresentam escassa capacidade de intervenção nas transformações da empresa, em razão dos frágeis vínculos sociais.

\section{Relações interfirmas}

As redes de empresas compõem-se de uma estrutura de posiçóes e de um sistema de relações. A dispersão do processo produtivo entre empresas resulta na criação de uma estrutura de posições hierarquizadas e com características variáveis. As relações interfirmas podem ser definidas como as relações de poder estabelecidas entre uma empresa contratante e uma empresa contratada, consideradas também como atores sociais, para a execução/ fornecimento de um serviço/ produto, envolvendo, portanto, não apenas interesses econômicos, de maximização do lucro, mas também a institucionalidade e as circunstâncias sócio-político-culturais a que pertencem.

A literatura examinada aponta dois padrões de relacionamento interfirmas: o de cooperação e o de subordinação. Haveria três parâmetros para classificar tais relações: a negociação dos vínculos, o intercâmbio e a confiança entre firmas. As relações interfirmas de cooperação caracterizarse-iam por favorecer a melhoria da qualidade de produtos e de serviços, através de intercâmbios técnico-organizacionais, de laços de confiança e de negociação das condições de vínculo entre as partes. As relações interfirmas de subordinação caracterizar-se-iam por forte assimetria de poder entre as empresas, sem trocas técnico-organizacionais, por laços instáveis e conflituosos e por imposição de condições de vínculo entre empresas (Faria, 1994; Gitahy, 1994; Gitahy et al., 1997; Gitahy e Cunha, 1999). 
Haveria a contribuição de dois fatores para a definição das propriedades das relações interempresas. O primeiro seria a estratégia competitiva da empresa central: estratégias voltadas para a qualidade dos serviços induziriam relações de cooperação entre empresas; estratégias apoiadas na competição via redução de custos induziriam relações de subordinação entre as partes (Faria, 1994; Gitahy, 1994; Gitahy et al., 1997). O segundo fator seria o tipo de serviço prestado pela empresa contratada: quanto maior a complexidade técnica do produto externalizado, maiores seriam as chances das relações interfirmas se estabelecerem cooperativamente, em razão do processo de produção exigir capacitação, coordenação e troca de informações, para o aperfeiçoamento do produto e para atualização tecnológica (Gitahy e Cunha, 1999). Então, de um lado, a estratégia competitiva da empresa central (resultante da interação entre as características do mercado, do tipo de serviço final, da forma de exploração da força de trabalho e das instituições), que orienta a realização do objetivo da rede (produzir mercadorias competitivas), e, de outro lado, o tipo de serviço prestado pelas empresas contratadas, que se associa às condições de mercado, à tecnologia empregada e à qualificação da mão-de-obra, definem as propriedades das diversas posições existentes na estrutura da rede e das relações entre empresas.

A estrutura da rede, bem como os dados sobre o tipo de serviços fornecidos, o número de empregados e o faturamento, em 1999, das empresas estudadas, são apresentados na Figura $1^{7}$. A estrutura da rede de empresas investigada é composta por diferentes segmentos e por distintos níveis de fornecedores. Os segmentos de fornecedores são os grupos de empresas subcontratadas para a execução de frações especializadas de tarefas, geradas pela divisão horizontal do processo produtivo: atendimento aos clientes; vigilância; fotocópias; manutenção dos sistemas elétricos, hidráulicos e de refrigeração dos prédios; instalação e manutenção de termi-

7 Os segmentos foram diferenciados por letras do alfabeto: " $\mathrm{A}$ " representa o segmento de digitalização das centrais de comutação, " $\mathrm{B}$ " o de infra-estrutura e " $\mathrm{C}$ " o de instalação de terminais. Os níveis foram distinguidos por números romanos: "I" representa o primeiro nível de fornecedores, "II" o segundo nível, "III" o terceiro nível e "IV" o quarto nível. No caso do segmento C, nível II, investigaram-se duas empresas, que foram classificadas pelos números cardinais " 1 " e " 2 ". 
nais telefônicos públicos, comerciais e residenciais; construção de redes de fibra óptica e de cabo metálico (infra-estrutura); instalação e digitalização de centrais de comutação telefônica. A investigação deteve-se no estudo de três segmentos de fornecedores cujos tipos de serviços prestados apresentam diferentes graus de complexidade técnica: digitalização de centrais de comutação, construção de redes de fibra óptica e de cabos metálicos (infra-estrutura) e instalação de terminais telefônicos.

Figura 1. Organograma da rede de empresas investigadas

Fonte: Pesquisa empírica, Região Metropolitana de Porto Alegre, 2000.

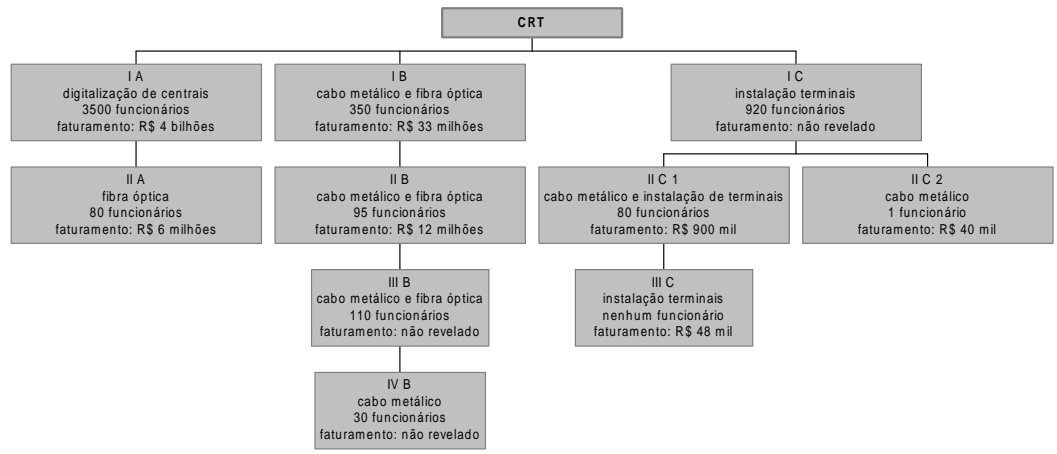

Os níveis de fornecedores são as sucessivas camadas de empresas subcontratadas, em face da divisão vertical do processo produtivo. A empresa central terceiriza diferentes tarefas a "empresas terceiras" (primeiro nível de fornecedores), as quais, por sua vez, terceirizam tarefas a "empresas quartas" (segundo nível), e assim sucessivamente. A investigação limitou-se ao primeiro e ao segundo níveis de fornecedores, no segmento de digitalização de centrais, e ao primeiro, ao segundo e ao terceiro níveis, no segmento de instalação de terminais, mas estendeu-se até o quarto nível de fornecedores no segmento de infra-estrutura.

A estrutura da rede sustenta-se em feixes de relaçôes interempresas. Conforme foi referido, há três parâmetros para a avaliação da natureza dessas 
relações: as condições de vínculo, o intercâmbio e os laços de confiança interempresas. As condiçôes de vínculo entre as empresas materializam-se nos contratos estabelecidos para a prestação de serviços. Os dados examinados estão resumidos no Quadro 1. A empresa central fixa contratos de curta duração para fomentar a concorrência e a redução de preços, em face da estratégia competitiva adotada. As variadas capacidades técnicas das empresas, no entanto, revertem-se em frágil tendência à maior duração dos vínculos para a manutenção de equipamentos de alta tecnologia (l A). As empresas terceiras não conseguem impor-se nesse aspecto, valendo as regras da empresa central. O tipo de serviço contratado interfere na disposição da empresa central em negociar os prazos de entrega: a empresa prestadora dos serviços mais complexos, a I A, consegue negociar prazos, enquanto a empresa prestadora dos serviços mais simples tecnicamente (I C) é penalizada, caso não cumpra os prazos estipulados. As três empresas terceiras pesquisadas apresentam diferentes situações de mercado e de administração interna. Quanto ao mercado, a maior complexidade técnica dos serviços prestados dotam a empresa de maior capacidade para diversificar a clientela e, por conseguinte, para tornarse independente da rede. Quanto às práticas administrativas, o grau de dependência da rede ao mercado (relacionado ao tipo de serviço prestado) associado à autonomia administrativa concedida pela empresa contratante implica liberdade para as empresas reduzirem custos na forma desejada: seja por meio de flexibilidade e de eficiência organizacional, seja burlando a lei.

Então, os dados explorados indicam que as formas de execução dos contratos e dos serviços pelas empresas terceiras da CRT não são homogêneas, variando de acordo com o tipo de serviço prestado. Por um lado, a estratégia competitiva de redução de custos adotada pela empresa central estimula a fixação unilateral de condições de vínculo entre as empresas (contratos de curta duração, ausência de diálogo para revisão de prazos, exigência de baixos custos, através de "autonomia" para práticas administrativas eficientes ou restritivas). Por outro lado, as empresas terceiras estão investidas de diferentes capacidades de reversão das condições de vínculo 
pretendidas pela empresa central: a I A mantém os contratos mais duradouros, negocia prazos e goza de independência administrativa e de mercado, o que não se verifica nos casos da I B e, sobretudo, da I C.

Quadro 1. Execução dos contratos firmados entre empresa central e empresas terceiras

\begin{tabular}{|c|c|c|c|}
\hline Indicadores & I A & I B & I C \\
\hline $\begin{array}{l}\text { Duração dos } \\
\text { contratos }\end{array}$ & $\begin{array}{l}\text { - Equipamentos } \\
\text { especializados: } \\
\text { indeterminada; } \\
\text { - Manutenção centrais: } \\
\text { indeterminada, desde a } \\
\text { década de } 60 ; \\
\text { - Instalação de } \\
\text { centrais: prazo } \\
\text { determinado ( } 2 \text { a } 6 \\
\text { meses). }\end{array}$ & $\begin{array}{l}\text { Obras de infra- } \\
\text { estrutura: prazo } \\
\text { determinado (em torno } \\
\text { de } 12 \text { meses). }\end{array}$ & $\begin{array}{l}\text { Instalação e } \\
\text { manutenção de } \\
\text { terminais: após } \\
\text { seleção, curtos } \\
\text { contratos renováveis } \\
\text { por regiões (alguns } \\
\text { contratos vigoram } \\
\text { desde 1997, a maioria, } \\
\text { entretanto, vigora a } \\
\text { partir de 1999). }\end{array}$ \\
\hline $\begin{array}{l}\text { Negociação dos } \\
\text { prazos }\end{array}$ & Sim. & $\begin{array}{l}\text { Não se dispõe de } \\
\text { informações fidedignas. }\end{array}$ & $\begin{array}{l}\text { Não: há multas por } \\
\text { atraso. }\end{array}$ \\
\hline $\begin{array}{l}\text { Autonomia } \\
\text { administrativa e } \\
\text { de mercado } \\
\text { Fonte: Pesquisa empíri }\end{array}$ & 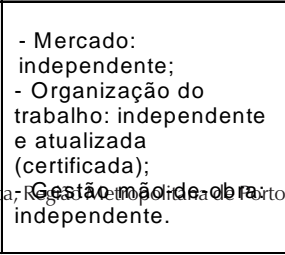 & $\begin{array}{l}\text { - Mercado: } \\
\text { parcialmente } \\
\text { independente } \\
\text { - Organização do } \\
\text { trabalho: independente } \\
\text { e semi-atualizada } \\
\text { (combina práticas } \\
\text { Aflegxávøioø rígidas); } \\
\text { - Gestão mão-de-obra: } \\
\text { há restrições. }\end{array}$ & $\begin{array}{l}\text { - Mercado: dependente } \\
\text { - Organização do } \\
\text { trabalho: independente } \\
\text { e rígida; } \\
\text { - Gestão mão-de-obra: } \\
\text { há restrições. }\end{array}$ \\
\hline
\end{tabular}

O intercâmbio entre as partes expressa-se pela troca de informações técnicas e de mercado, pela troca de equipamentos e por programas conjuntos para treinamento e formação de mão-de-obra. O Quadro 2 resume e sistematiza os dados relativos às empresas investigadas. Não são estimuladas pela CRT práticas de intercâmbio técnico ou de mercado entre as empresas da rede. Existe interação técnica com a empresa I A, mas deve-se mais à especificidade e à complexidade do serviço prestado do que ao interesse da CRT em fomentar o intercâmbio interempresas. Segundo uma estratégia competitiva de redução de custos, torna-se de interesse da empresa central da rede a fragmentação das informações, como forma de estímulo à concorrência e à redução de valores para os serviços. A compe- 
tição interfirmas obstaculiza a cooperação para a troca de equipamentos e de ferramentas. A cooperação efetiva para treinamento de mão-de-obra limita-se ao caso de serviços de alta complexidade técnica (I A).

Então, a estratégia competitiva de redução de custos empregada pela CRT não estimula práticas de intercâmbio interfirmas: a empresa central exime-se de práticas voltadas para o comprometimento mútuo, na medida em que implicariam a elevação dos custos com trabalho terceirizado e exigiriam relativa fidelidade com algumas empresas, reduzindo o nível de competição entre as prestadoras de serviços. No entanto a especificidade e a complexidade técnica do serviço contratado, bem como a pressão das instituições, podem obrigar a empresa central ao exercício de práticas cooperativas: treinamento de mão-de-obra e interação técnica com a empresa I A, treinamento da força de trabalho terceirizada relativamente à segurança no trabalho.

Quadro 2. Intercâmbio interfirmas

\begin{tabular}{|l|l|l|l|}
\hline \multicolumn{1}{|c|}{ Indicadores } & \multicolumn{1}{|c|}{ I A } & \multicolumn{1}{c|}{ I B } & \multicolumn{1}{c|}{ I C } \\
\hline $\begin{array}{l}\text { Troca de } \\
\text { informações }\end{array}$ & $\begin{array}{l}\text { - técnicas: intensa; } \\
\text { mercado: não. }\end{array}$ & Não há intercâmbio. & Não há intercâmbio. \\
\hline $\begin{array}{l}\text { Troca de } \\
\text { equipamentos }\end{array}$ & Não ocorre. & Não ocorre. & $\begin{array}{l}\text { Não ocorre com a CRT, } \\
\text { mas com algumas } \\
\text { subcontratadas pela I C. }\end{array}$ \\
\hline $\begin{array}{l}\text { Treinamento } \\
\text { conjunto de } \\
\text { mão-de-obra }\end{array}$ & $\begin{array}{l}\text { Há treinamento } \\
\text { relativamente aos } \\
\text { produtos } \\
\text { desenvolvidos, } \\
\text { fornecido pela I A para } \\
\text { a CRT. }\end{array}$ & $\begin{array}{l}\text { Frágil cooperação para } \\
\text { segurança no trabalho. } \\
\text { Mas ocorrem parcerias } \\
\text { com outros clientes. }\end{array}$ & $\begin{array}{l}\text { Frágil cooperação para } \\
\text { segurança no trabalho. }\end{array}$ \\
\hline
\end{tabular}


Os laços de confiança interempresas são expressos na freqüência de realização das obras e dos serviços, no apoio prestado pela empresa contratante para a atualização tecnológica da empresa contratada e no apoio da empresa contratante para a reestruturação organizacional da empresa contratada. O Quadro 3 reúne as principais informações relativas aos laços de confiança entre a CRT e as empresas terceiras. A CRT mantém relativa estabilidade de vínculo com as empresas terceiras, mas em graus diferentes: a empresa I A mantém relações mais duradouras, embora com variabilidade (desde a década de 60), a empresa I B mantém relações menos extensas do que a I A e mais extensas do que a I C (desde 1995, continuamente) e a empresa I C mantém as relações menos extensas (desde 1997, em expansão). A CRT coopera tecnologicamente somente com a I A, pertencente ao segmento mais complexo tecnicamente, que exige capacitação contínua. As mudanças organizacionais na CRT não vêm repercutindo em apoio, nem em exigência de reestruturação, ao longo da rede, embora haja a tendência de as empresas I A e I B, cujos tipos de serviços são mais complexos tecnicamente e diversificados (conseqüentemente, menos dependentes da rede), atualizarem as suas práticas organizacionais como forma de adquirir eficiência e competitividade no mercado.

Assim, os dados examinados indicam diferentes situações entre as empresas quanto aos laços de confiança, de acordo com o tipo de serviço que prestam. A estratégia competitiva de redução de custos da empresa contratante não induz ao apoio para a reestruturação organizacional, nem para a inovação/ atualização tecnológica, embora não venha impedindo a constituição de laços relativamente longos. Contudo, o segmento a que pertencem as empresas afetou diferentemente as suas situações nos três indicadores. 
Quadro 3. Confiança interempresas

\begin{tabular}{|l|l|l|l|}
\hline \multicolumn{1}{|c|}{ Indicadores } & \multicolumn{1}{|c|}{ I A } & \multicolumn{1}{c|}{ I B } & \multicolumn{1}{c|}{ I C } \\
\hline $\begin{array}{l}\text { Freqüência } \\
\text { serviços }\end{array}$ & $\begin{array}{l}\text { - manutenção centrais: } \\
\text { continuidade desde a } \\
\text { década de 60; } \\
\text { - construção de novas } \\
\text { centrais: baixa } \\
\text { variação. }\end{array}$ & $\begin{array}{l}\text { Há continuidade nos } \\
\text { serviços desde 1995. }\end{array}$ & $\begin{array}{l}\text { Presta serviços } \\
\text { continuamente desde } \\
1997, \text { ampliando-se em } \\
1999, \text { embora com } \\
\text { variação na demanda. }\end{array}$ \\
\hline $\begin{array}{l}\text { Apoio para } \\
\text { atualização } \\
\text { tecnológica }\end{array}$ & $\begin{array}{l}\text { "Parcerias" para } \\
\text { desenvolvimento de } \\
\text { novos produtos } \\
\text { cooperação ad hoc). }\end{array}$ & $\begin{array}{l}\text { Não há programas de } \\
\text { cooperação com a } \\
\text { CRT, mas existe } \\
\text { "parceria" com outro } \\
\text { cliente. }\end{array}$ & Não há cooperação. \\
\hline $\begin{array}{l}\text { Apoio para } \\
\text { reestruturação } \\
\text { organizacional }\end{array}$ & $\begin{array}{l}\text { Não há apoio, mas a } \\
\text { empresa é certificada } \\
\text { em diferentes setores, } \\
\text { inclusive }\end{array}$ & $\begin{array}{l}\text { Não há apoio, nem } \\
\text { exigência de } \\
\text { reestruturação. Mas, a } \\
\text { empresa possui } \\
\text { telecomunicações. } \\
\text { certificação e apoio de } \\
\text { outro cliente. }\end{array}$ & $\begin{array}{l}\text { Não há apoio, nem } \\
\text { exigência de } \\
\text { reestruturação. }\end{array}$ \\
\hline
\end{tabular}

Fonte: Pesquisa empírica, Região Metropolitana de Porto Alegre, 2000.

As instâncias empíricas relativas aos três parâmetros examinados evidenciam distintos padrões de relacionamento interfirmas na rede de empresas estudada. Os parâmetros utilizados para medir o grau de cooperação/ subordinação nas relações entre as empresas apresentam características associadas à estratégia competitiva da empresa contratante e ao tipo de serviço prestado pela empresa contratada. Desse modo, em contexto de estratégia competitiva de redução de custos, quanto maior a complexidade técnica dos serviços prestados, maiores as possibilidades de as empresas contratadas negociarem as condições de vínculo, estabelecerem práticas de intercâmbio e desenvolverem laços de confiança, com as empresas contratantes. Podemse, para fins analíticos, classificar em três tipos as relações interempresas encontradas: relações de cooperação, relações de subordinação por conveniência e relações de subordinação por dependência. Os principais traços das relações tipificadas são esquematizados no Quadro 4. 
As relações interfirmas de cooperação caracterizam-se empiricamente por forte negociação das condições de vínculo (vínculo indeterminado para manutenção, mas contratos de curta duração para obras; negociação de prazos de entrega; autonomia de mercado e administrativa), por intercâmbio moderado (troca de informações técnicas, mas não de mercado; sem troca de equipamentos; cooperação para treinamento de mão-de-obra) e por fortes laços de confiança (obras constantes desde 1996; desenvolvimento conjunto de novos produtos; ausência de apoio para a reestruturação organizacional, mas a empresa é certificada no ramo de telecomunicações). Trata-se das relações com a menor assimetria de poder entre as tipificadas. A complexidade e a especificidade técnica dos serviços envolvidos impõem práticas de cooperação entre as partes.

Quadro 4. Tipos de relações interfirmas

\begin{tabular}{|l|l|l|l|}
\hline & \multicolumn{1}{|c|}{$\begin{array}{c}\text { Relações de } \\
\text { cooperação }\end{array}$} & $\begin{array}{c}\text { Relações de } \\
\text { subordinação por } \\
\text { conveniência }\end{array}$ & $\begin{array}{c}\text { Relações de } \\
\text { subordinação por } \\
\text { dependência }\end{array}$ \\
\hline $\begin{array}{l}\text { Negociação das } \\
\text { condições de } \\
\text { vínculo }\end{array}$ & Forte & Moderada & Inexistente \\
\hline Intercâmbio & Moderado & $\begin{array}{l}\text { Fraco, quase } \\
\text { inexistente }\end{array}$ & Fraco, quase inexistente \\
\hline Confiança & Moderada & Fraca & Fraca, quase inexistente \\
\hline
\end{tabular}

Fonte: Composição a partir de pesquisa empírica, Região Metropolitana de Porto Alegre, 2000.

As relações interfirmas de subordinação por conveniência caracterizamse empiricamente por moderada negociação das condições de vínculo (contratos relativamente extensos; ausência de negociação de prazos de entrega; relativa autonomia de mercado e administrativa), por intercâmbio fraco, quase inexistente (ausência de troca de informações; sem empréstimo de equipamentos; frágil cooperação para treinamento de mão-de-obra) e por fracos laços de confiança (obras constantes, desde 1995; ausência de apoio para 
inovação tecnológica e para reestruturação organizacional, apesar de a empresa vir reestruturando-se em outros segmentos de atuação). Trata-se de relações com maior assimetria de poder do que as de cooperação e menor do que as de subordinação por dependência. Nesse caso, a subordinação ocorre em face da predominância dos interesses da empresa contratante sobre os da contratada, mas por conveniência para ambas as partes: para a empresa contratante é conveniente utilizar os serviços relativamente complexos da contratada, desde que nas condições financeiras orientadas por sua estratégia competitiva; para a empresa contratada é conveniente prestar serviços sob as condições financeiras da contratante, desde que esta mantenha certa estabilidade de vínculo e diversificação de clientes.

As relações interfirmas de subordinação por dependência caracterizam-se empiricamente pela ausência de negociação das condições de vínculo (contratos de curta duração; ausência de negociação de prazos de entrega; dependência de mercado e administrativa), por intercâmbio fraco, quase inexistente (sem troca de informações ou de equipamentos; frágil cooperação para treinamento de mão-de-obra) e por fracos, quase inexistentes laços de confiança (prestação freqüente de serviços, desde 1997; ausência de apoio para inovação tecnológica e para reestruturação organizacional). Essas são as relações com maior assimetria de poder. A empresa contratada aceita as condições da contratante, porquanto depende do mercado da rede, na medida em que presta um serviço de baixa complexidade e amplamente oferecido no mercado.

A interação e a conflitualidade entre os interesses da empresa contratante, orientados pela estratégia competitiva, e a capacidade de resistência/ imposição das empresas contratadas, relacionada ao tipo de serviços prestados, resultam em dispersão do processo produtivo em uma estrutura diferenciada e fragmentada, vertical e horizontalmente, e em diferentes padrões de relacionamento interempresas. A estratégia competitiva de redução de custos adotada pela CRT abriu um campo de possibilidades para a estruturação da rede (múltiplas posições derivadas da existência de diferentes segmentos e níveis de fornecedores), que foram realizadas distinta- 
mente pelas empresas, em razão de suas características (tecnologia empregada, situação de mercado, qualificação de mão-de-obra, que convergem nos tipos de serviços prestados). Daí a multiformidade verificada nas relações interfirmas. Portanto, relações interfirmas envolvem variável distribuição de poder e diferentes formas de compatibilização dos divergentes interesses dos atores sociais (cooperação/ subordinação).

\section{Emprego}

A diversificação da estrutura empresarial na forma de rede - em múltiplos níveis e segmentos de fornecedores - e os variados padrões de relacionamento interfirmas - resultantes da crescente externalização de atividades de alta e de baixa tecnologia e qualificação, e dos diferentes ambientes sociais nos quais as redes se realizam - implicam a multiformidade do emprego: a rede de empresas pode envolver tanto formas precárias de emprego como não-precárias.

Uma parte dos estudos examinados afirmam que, no Brasil, o trabaIho nas empresas contratadas caracteriza-se por extensas jornadas de trabaIho, por despreocupação com a qualificação e o treinamento da mão-deobra, por altas taxas de rotatividade e de trabalho temporário, por perda dos direitos trabalhistas, por situações de risco à saúde e à segurança e por enfraquecimento dos sindicatos (Borges e Druck, 1993; Dedecca, 1996; Druck, 1999; Martins, 1994). No entanto outras pesquisas relativizam essas conclusões, na medida em que encontraram características como ativa participação sindical, baixa rotatividade, utilização de mão-de-obra qualificada e bem treinada e manutenção dos principais direitos trabalhistas em empresas subcontratadas, sustentando que o caráter assumido pelo trabaIho nas empresas terceiras é variável, em face das diferentes circunstâncias que envolvem as empresas (Abreu et al., 1998; Gitahy e Cunha, 1999).

Haveria dois fatores condicionantes das práticas de emprego na rede de empresas. O primeiro seria a natureza das relações interfirmas. As relações interfirmas de cooperação favoreceriam práticas não-precárias de emprego, em face do estabelecimento de relações de confiança, estáveis e 
formalizadas, da negociação de prazos e valores e do envolvimento de mão-de-obra qualificada. As relações interfirmas de subordinação favoreceriam práticas precárias de emprego, em razão do uso intensivo de mãode-obra não-qualificada, da competição por preço entre empresas contratadas, da instabilidade do vínculo e da grande informalidade das relações (Gitahy, 1994; Faria, 1994; Gitahy et al., 1997; Abreu et al., 1998). O segundo fator que concorreria para a definição das práticas de emprego seria a posição da empresa na rede. A desverticalização das grandes empresas (centrais) teria significado a externalização de partes importantes da produção a fornecedores diretos (terceiras), os quais, muitas vezes, articulam a sua produção a pequenos e médios fornecedores (quartas), resultando num novo nível de externalização (Castells, 1999; Dedecca, 1996; Wormald, 1999). Disso resultam diferentes níveis na rede de empresas: central, terceira, quarta, etc. Assim, quanto mais próxima da empresa central estiver a empresa contratada, maiores seriam as chances da adoção de práticas não-precárias de emprego. O Quadro 5 esquematiza os dados relativos às práticas de emprego nas empresas da rede ${ }^{8}$.

Examinados os dados relativos às empresas terceiras da rede segundo o tipo de relações estabelecidas com a empresa central, verifica-se que a empresa I A foi a que apresentou melhor desempenho nos indicadores analisados: baixa rotatividade; vínculo formal e de longa duração (permanente); remuneração fixa e participação nos lucros da empresa, com valores superiores para a função de técnico e inferiores para as funções de cabista e de instalador, comparativamente às demais empresas terceiras; amplo programa de benefícios sociais.

A empresa I B apresentou uma situação intermediária: baixa rotatividade; vínculo formal, mas combinando emprego temporário e permanente; remuneração fixa e participação nos lucros da empresa; benefícios sociais maiores do que a I C, porém menores do que a I A.

8 Coletaram-se dados também sobre a jornada de trabalho nas empresas. No entanto as diferenças constatadas não foram significativas. 
Quadro 5. Condições de emprego nas empresas da rede

\begin{tabular}{|c|c|c|c|c|}
\hline Empresa & Remuneração mensal & Benefícios sociais & Vínculo & $\begin{array}{l}\text { Rotativida } \\
\text { de (mês) }\end{array}$ \\
\hline Central & $\begin{array}{l}\text { - salário + PLR } \\
\text { - técnicos: } R \$ 2100,00\end{array}$ & $\begin{array}{l}\text { Tíquete refeição, cesta } \\
\text { básica, transporte, plano } \\
\text { médico, incentivo à } \\
\text { educação, auxílio materno } \\
\text { infantil e outros. }\end{array}$ & $\begin{array}{l}\text { - formal } \\
\text { - indeterminado }\end{array}$ & $0,8 \%$ \\
\hline IA & $\begin{array}{l}\text { - salário + PLR } \\
\text { - técnicos: } \mathrm{R} \$ 1500,00 ; \\
\text { cabistas: } \mathrm{R} \$ 800,00 ; \mathrm{e} \\
\text { instaladores: } \mathrm{R} \$ 500,00 \text {. }\end{array}$ & $\begin{array}{l}\text { Complemento } \\
\text { previdenciário, plano } \\
\text { médico e odontológico, } \\
\text { vale-transporte e tíquete } \\
\text { refeição. }\end{array}$ & $\begin{array}{l}\text { - formal } \\
\text { - indeterminado }\end{array}$ & $2,5 \%$ \\
\hline IB & $\begin{array}{l}\text { - salário + PLR } \\
\text { - valor não informado. }\end{array}$ & $\begin{array}{l}\text { Plano médico; vale- } \\
\text { transporte; tíquete refeição; } \\
\text { farmácia. }\end{array}$ & $\begin{array}{l}\text { - formal } \\
\text { - temporário e } \\
\text { permanente }\end{array}$ & $2,8 \%$ \\
\hline IC & $\begin{array}{l}\text { - por produção } \\
\text { - técnicos: } \mathrm{R} \$ 800,00 ; \\
\text { cabistas: } \mathrm{R} \$ 2000,00 ; \\
\text { instaladores: } \mathrm{R} \$ 1500,00 \text {. }\end{array}$ & $\begin{array}{l}\text { Vale-transporte, tíquete- } \\
\text { refeição, plano médico. }\end{array}$ & $\begin{array}{l}\text { - semiformal } \\
\text { - temporário e } \\
\text { permanente }\end{array}$ & $\begin{array}{l}20 \% \text { para } \\
\text { instaladores }\end{array}$ \\
\hline$\| \mathrm{A}$ & $\begin{array}{l}\text { - salário } \\
\text { - técnico: } R \$ 800,00 \\
\text { cabista: } R \$ 750,00 \text {. }\end{array}$ & $\begin{array}{l}\text { Vale-transporte, tíquete- } \\
\text { refeição, plano médico. }\end{array}$ & $\begin{array}{l}\text { - formal } \\
\text { - temporário e } \\
\text { permanente }\end{array}$ & $2,5 \%$ \\
\hline II B & $\begin{array}{l}\text { - salário + produção } \\
\text { - técnico: } R \$ 600,00 ; \text { cabista } \\
\text { e instalador: } R \$ 1500,00 \text {. }\end{array}$ & $\begin{array}{l}\text { Vale-transporte, tíquete- } \\
\text { refeição, cesta básica, } \\
\text { plano médico e } \\
\text { odontológico. }\end{array}$ & $\begin{array}{l}\text { - semiformal } \\
\text { - indetermi-nado }\end{array}$ & $5,2 \%$ \\
\hline II C 1 & $\begin{array}{l}\text { - salário + produçãa } \\
\text { - cabista: } \mathrm{R} \$ 800,00 ; \\
\text { instalador: } \mathrm{R} \$ 700,00 \text {. }\end{array}$ & $\begin{array}{l}\text { Vale-transporte, tíquete- } \\
\text { refeição. }\end{array}$ & $\begin{array}{l}\text { - semiformal } \\
\text { - indetermi-nado }\end{array}$ & $12,5 \%$ \\
\hline II C 2 & $\begin{array}{l}\text { - por produção } \\
\text { - cabista: } \mathrm{R} \$ 800,00\end{array}$ & Não há. & $\begin{array}{l}\text { - informal } \\
\text { - indetermi-nado }\end{array}$ & $\begin{array}{c}\text { Apenas } 1 \\
\text { funcionário. }\end{array}$ \\
\hline III B & $\begin{array}{l}\text { - salário } \\
\text { - cabista: } \mathrm{R} \$ 450,00 ; \\
\text { instalador: } \mathrm{R} \$ 300,00 \text {. }\end{array}$ & $\begin{array}{l}\text { Vale-transporte, almoço, } \\
\text { plano médico e } \\
\text { odontológico. }\end{array}$ & $\begin{array}{l}\text { - formal } \\
\text { - temporário e } \\
\text { permanente }\end{array}$ & $18 \%$ \\
\hline III C & Não tem empregado. & Não tem empregado. & $\begin{array}{l}\text { Não tem } \\
\text { empregado. }\end{array}$ & $\begin{array}{l}\text { Não tem } \\
\text { empregado. }\end{array}$ \\
\hline IV B & $\begin{array}{l}\text { - salário } \\
\text { - cabista: } \mathrm{R} \$ 500,00 \text {; } \\
\text { instalador: } \mathrm{R} \$ 400,00 \text {. }\end{array}$ & $\begin{array}{l}\text { Vale-transporte e tíquete } \\
\text { refeição. }\end{array}$ & $\begin{array}{l}\text { - formal } \\
\text { - temporário e } \\
\text { permanente. }\end{array}$ & $\begin{array}{c}\text { Não } \\
\text { informado. }\end{array}$ \\
\hline
\end{tabular}


A empresa I C foi, entre as empresas terceiras, a que apresentou o pior desempenho nos indicadores examinados: elevada rotatividade; vínculo semiformalizado e combinando emprego temporário e permanente; remuneração por produção, que induz à extensão da jornada de trabalho e ao vínculo informal, porém com valores brutos superiores às demais empresas para as funções de cabista e de instalador e com valores brutos inferiores para a função de técnico; e benefícios sociais escassos. Observe-se que os amplos benefícios sociais e a formalização integral do vínculo empregatício relativizam a menor remuneração paga pela I A para as funções de instalador e de cabista, quando comparadas à remuneração paga pela I C.

Por conseguinte, o intercâmbio e a confiança entre as empresas permite à parte contratada planejar e estabilizar as práticas de emprego, em face da extensão e do apoio no vínculo interempresas, assim como a negociação das condições contratuais possibilita a obtenção de melhores valores contratados, permitindo a oferta de mão-de-obra mais qualificada e com melhores condições de emprego. Os dados autorizam a afirmação de que quanto maior a cooperação nas relações interfirmas, tanto maiores serão as chances de as empresas contratadas estabelecerem práticas não-precárias de emprego.

A negociação das condições de vínculo interempresas incide sobre a temporalidade do vínculo empregatício, na medida em que a empresa contratada pode ampliar prazos e reduzir a dependência em relação à empresa contratante (mantendo trabalhadores empregados) e sobre o valor da remuneração, pois é possível a obtenção de melhores preços para a execução dos serviços. O intercâmbio entre as empresas interfere na natureza da formação e na instrução dos trabalhadores (treinamento conjunto fomenta a formação teórica da mão-de-obra e exige maior instrução dos treinandos, bem como troca de informações técnicas exige equivalência na formação dos recursos humanos) e na rotatividade da mão-de-obra (a cooperação para formação de mão-de-obra implica investimento nos recursos humanos 
e no conseqüente esforço para a sua manutenção). A confiança nos laços interempresas repercute na rotatividade (laços de confiança tornam os serviços mais freqüentes, permitindo a manutenção da força de trabalho empregada), na natureza da formação profissional (o apoio tecnológico e organizacional torna mais complexo o processo produtivo, exigindo mãode-obra instruída e com formação teórica) e na formalização do vínculo (a estabilidade dos laços entre as empresas, a atualização técnica e organizacional estimula a formalização da mão-de-obra).

A posição da empresa nos níveis da rede também interfere nas práticas de emprego. A rotatividade tende a aumentar à medida que avançam os níveis da rede, embora irregularmente, pois no segmento de digitalização não houve crescimento da rotatividade do I para o II nível e, no segmento de instalação de terminais, a rotatividade foi maior no I do que no II nível, como se observa no Quadro 5.

A remuneração tende a apresentar caráter mais simples e restritivo, conforme os níveis de empresas se distanciem da empresa líder da rede, assumindo a forma de remuneração fixa, e/ou por produção, em detrimento de formas de remuneração mais complexas, como a PLR (Participação nos Lucros e Resultados). A PLR permite à força de trabalho maior esclarecimento acerca do valor gerado e da retribuição monetária por seu trabalho, além de favorecer a formalização da remuneração, na medida em que se apóia em registros contábeis, embora passível de dissimulação. Os valores da remuneração mensal também são variáveis, com tendência de queda com o avanço nos níveis da rede, exceto do nível III para o IV, no segmento de infra-estrutura. Todavia interferem, nos valores da remuneração, os benefícios sociais que os complementam e a natureza do vínculo trabalhista (formal/ informal) que implicam gastos indiretos com a mão-deobra (impostos, benefícios, contribuição previdenciária, férias, FGTS). Então, a remuneração assume maior significado na análise, se associada aos benefícios sociais e ao vínculo empregatício. 
Quanto ao vínculo trabalhista, há, de um lado, leve tendência de ampliação das situações de informalidade nos vínculos, com o aumento dos níveis da rede e, de outro lado, grande irregularidade na temporalidade do vínculo, sem relação significativa com os níveis da rede. Os benefícios sociais reduzem-se significativamente à proporção que aumentam os níveis da rede.

Por conseqüente, o emprego precariza-se à proporção que aumentam os níveis da rede. Os múltiplos atores empresariais envolvidos têm, por um lado, menor dificuldade para burlar legislações, ou contratos, e menor controle da qualidade dos serviços prestados, e, por outro lado, são mais estimulados a reduzirem custos, utilizando mão-de-obra não-qualificada e em condições de precariedade quanto mais distantes da empresa líder se encontrarem.

Tais conexões ocorrem pelo fato de que as diferentes posições nos níveis da rede influem nos valores pagos pelos serviços prestados, no volume de serviços e no controle de contratos e da legislação. A retração dos valores pagos pelos serviços pressiona as empresas para a redução da remuneração e dos benefícios sociais. A maior variabilidade no volume de serviços contratados repercute em instabilidade na gestão dos recursos humanos: maior rotatividade e dificuldades para treinamento de mão-deobra. O afrouxamento do controle e da fiscalização dos contratos e da legislação, que ocorre à medida que as empresas assumem posições mais periféricas na rede, facilita a informalidade do vínculo, o corte de benefícios sociais e práticas paternalistas de negociação entre capital e trabalho.

Portanto, os dados relativos aos indicadores examinados evidenciam a existência de divergentes práticas de emprego ao longo da rede: precárias, não-precárias e combinações de práticas precárias e não-precárias. Tal multiformidade se deve tanto aos distintos padrões de relacionamento interfirmas como à fragmentação vertical do processo produtivo em diversos níveis de fornecedores. 


\section{Considerações finais}

A rede de empresas pode combinar diferentes padrões de relacionamento interfirmas e de emprego, porquanto suas características dependem da conjugação de fatores técnicos, econômicos, societais e políticos. No caso da rede investigada, constatou-se que a interação entre a estratégia competitiva da empresa contratante apoiada na redução de custos (que expressa as condições oferecidas às empresas contratadas) e os diferentes tipos de serviços prestados pelas empresas contratadas, com variados níveis de complexidade tecnológica (que expressam as suas variadas capacidades de imposição à empresa contratante), resulta em três tipos de relacionamento interempresas (de cooperação, de subordinação por conveniência e de subordinação por dependência) e em diversos níveis/ camadas de fornecedores (empresas terceiras, quartas, quintas e sextas) e que as diferentes relações interfirmas e as posições das empresas nos níveis da rede implicam a existência de práticas precárias e não-precárias de emprego, ao longo da rede.

Desse modo, as relações interfirmas e o emprego na rede de empresas apresentam-se multiformemente: a rede é compatível tanto com relações cooperativas e com emprego não-precário quanto com relações subordinativas e com emprego precário. Tal multiformidade somente é apreendida desde uma perspectiva não-dualista, que considere a multidimensionalidade na definição das características da rede de empresas. Os arranjos da rede dependem tanto de constrangimentos derivados do ambiente social, inclusive da dinâmica de mercado, como das estratégias e interesses específicos dos múltiplos atores sociais envolvidos.

Quais serão as repercussões para a CRT da estratégia competitiva e das relações estabelecidas com os fornecedores pela GVT, sua concorrente? O controle mais eficiente do setor por parte de instituições sociais mais amplas (seja a Anatel, seja o Estado) porventura não afetaria a rede? A ampliação da ação sindical rumo à periferia da rede e às outras empresas do setor não interferirá no emprego na rede? 
Os atores sociais envolvidos no universo do trabalho enfrentam, pois, uma nova e desafiadora realidade na contemporaneidade: ainda dramaticamente desigual, porém mais fragmentada, dinâmica e flexível, expressa em parte na multiformidade e na multidimensionalidade das tramas produtivas que se configuram em face da externalização de trabalho, como supra analisado.

Essa nova realidade exige, para a apreensão de toda a sua extensão, por um lado, a ampliação da unidade de análise da empresa - própria para a apreensão da produção fordista verticalizada - para a rede de empresas adequada para a reflexão sobre a dinâmica da produção flexível; e, por outro lado, a crítica às abordagens homogeneizantes que apreendem apenas parcialmente o fenômeno em questão - sejam as que argumentam que a externalização origina arranjos empresariais cooperativos e práticas nãoprecárias de emprego, sejam as que sustentam que a externalização origina arranjos de subordinação interempresas e práticas precárias de emprego, ao longo de toda a rede.

\section{Referências}

ABREU, Alice R. de P. et al.. Os impactos sociais da terceirização industrial no Rio de Janeiro: um estudo de caso no setor de telecomunicações. In: CASTRO, N. e DEDECCA, C. S. (orgs.). A ocupação na América Latina: tempos mais duros. São Paulo; Rio de Janeiro: Associação Latino-americana de Sociologia do Trabalho, 1998, p. 155-188 (Série II Congresso Latino-americano de Sociologia do TrabaIho).

BORGES, Ângela e DRUCK, Maria da G. Crise global, terceirização e exclusão no mundo do trabalho. Caderno CRH, O mundo do trabalho e dos trabalhadores, Salvador, n.19, jul/dez de 1993, p. 22-45.

CASTELLS, Manuel. A sociedade em rede. São Paulo: Paz e Terra, 1999.

COUTINHO, L. et al.. Introdução: telecomunicações, globalização e competitividade. In: COUTINHO, L Telecomunicações, globalização e competitividade. Campinas: Papirus, 1995, p. 13-38. 
DEDECCA, C. S.. Racionalização econômica e heterogeneidade nas relações e nos mercados de trabalho no capitalismo avançado. In: BARBOSA DE OLIVEIRA et al.. Crise e trabalho no Brasil: modernidade ou volta ao passado? São Paulo: Scritta, 1996, p. 55-86.

DIEESE. Terceirização dos serviços da CRT. Porto Alegre: Sub-seção Sinttel / Dieese, novembro de 2000 (mimeo).

DRUCK, Maria da G. Terceirização: (des)fordizando a fábrica. Um estudo do complexo petroquímico. Salvador: Boitempo, 1999.

FARIA, Aparecido de. Terceirização: um desafio para o movimento sindical. In: MARTINS, Heloísa de S. e RAMALHO, José R. (orgs.). Terceirização: diversidade e negociação no mundo do trabalho. São Paulo: Hucitec, 1994. p. 41-61.

GAZETA MERCANTIL. Análise setorial: telecomunicações. Vol. I. São Paulo: Gazeta Mercantil, 1997.

GEREFFI, Gary. Competitividade e redes na cadeia produtiva do vestuário da América do Norte. Revista Latinoamericana de estudios del trabajo: uma nova trama produtiva? Competitividade, novos atores e relações interfirmas, São Paulo, ano 3, n. 6, 1997, p. 101-127.

GITAHY, Leda e CUNHA, Adriana M. de. Redes y flexibilidad: restruturación productiva y trabajo en la industria de línea blanca. In: MONTERO, Cecília; ALBUQUERQUE, Mario e ENSIGNIA, Jaime (orgs.). Trabajo y empresa: entre dos siglos. Caracas: Nueva Sociedad, 1999. p. 79-103.

GITAHY, Leda et al.. Relações interfirmas, eficiência coletiva e emprego em dois clusters da indústria brasileira. Revista Latinoamericana de estudios del trabajo: uma nova trama produtiva? Competitividade, novos atores e relações interfirmas, São Paulo, ano 3, n. 6, 1997, p. 37-78.

GITAHY, Leda. Inovação tecnológica, relações interfirmas e mercado de trabalho. In: GITAHY, Leda (org.). Reestructuracion productiva, trabajo y educacion en America Latina. Campinas: IG / Unicamp, 1994, p. 123-136.

LARANGEIRA, Sônia M. G.. Reestruturação no setor de telecomunicações: aspectos da realidade internacional. Revista Latinoamericana de estudios del trabajo: relações industriais, análises comparativas, São Paulo, ano 4, n. 8, 1998 b. 
Sociologias, Porto Alegre, ano 4, no 8, jul/dez 2002, p. 400-431

MARTIN, Scott. Redes sociais e flexibilidade do trabalho: uma análise comparativa. Revista Latinoamericana de estudios del trabajo: uma nova trama produtiva? Competitividade, novos atores e relações interfirmas, São Paulo, ano 3, n.6, 1997, p. 9-38.

MARTINS, Heloísa de S. Os dilemas do movimento sindical em face da terceirização. In: MARTINS, Heloísa de S. e RAMALHO, José R. (orgs.). Terceirização: diversidade e negociação no mundo do trabalho. São Paulo: Hucitec, 1994, p. 13-40.

PASTE. Perspectivas para Ampliação e Modernização do Setor de Telecomunicações. Brasília: Ministério das Comunicações, 2000 (mimeo).

PASTE. Programa de Recuperação e Ampliação do Sistema de Telecomunicações e do Sistema Postal. Brasília: Ministério das Comunicações, 1997 (mimeo).

PESSINI, José E. e MACIEL, Cláudio S.. Modelos de regulação e políticas públicas em telecomunicações. In: COUTINHO, Luciano et al. Telecomunicações, globalização e competitividade. Campinas: Papirus, 1995, p. 273-333.

RUDUIT, Sandro. Relações interfirmas e emprego: estudo de uma rede de empresas em telecomunicações. Dissertação de mestrado. Porto Alegre: Programa de Pós-Graduação em Sociologia / UFRGS, 2001.

WALTER, Jorge. Privatizaciones y relaciones laborales en la telefonía latinoamericana. Revista Latinoamericana de estudios del trabajo: relações industriais, análises comparativas, São Paulo, ano 4, n. 8, 1998, p. 89-107.

WORMALD, Guillermo. De las pirámides a las redes. In: MONTERO, Cecília; ALBUQUERQUE, Mario e ENSIGNIA, Jaime (orgs.). Trabajo y empresa: entre dos siglos. Caracas: Nueva Sociedad, 1999, p. 59-63. 


\section{Resumo}

A reestruturação do setor de telecomunicações vem implicando a formação de estruturas empresariais na forma de rede. Neste artigo, examinam-se os padrões de relacionamento interfirmas e de emprego na rede de empresas liderada pela Companhia Riograndense de Telecomunicações (CRT). A análise abrange onze empresas, prestadoras de diferentes tipos de serviços (digitalização de centrais de comutação, cabeamento e instalação de terminais telefônicos) e localizadas em diversos níveis da rede ("empresas terceiras", "quartas", "quintas" e "sextas"). Conclui-se que existe grande diversidade no relacionamento interempresas (relacionadas à interação entre a estratégia competitiva da empresa central e os tipos de serviços prestados) e nas práticas de emprego (associadas às relações interfirmas e à posição das empresas nos níveis da rede).

Palavras-chave: reestruturação, rede de empresas, relações interfirmas, emprego, telecomunicações. 